\title{
Federal Wide Assurance
}

National Cancer Institute

\section{Source}

National Cancer Institute. Federal Wide Assurance. NCI Thesaurus. Code C62588.

Under the Department of Health and Human Services (DHHS) human subjects

protection regulations (at 45 C.F.R. 46.103), every institution eng aged in human subjects research that is funded or conducted by DHHS must obtain an Assurance Of Compliance approved by the Office for Human Research Protections (OHRP). This Assurance Of Compliance, when granted, is called a Federalwide Assurance. Both "awardee" institutions and collaborating "performance site" institutions must file Assurances. 